\title{
Gibson, B. E.: Rehabilitation: A Post-critical Approach
}

\author{
CRC Press, Boca Raton, 2016, 162 pp, $\$ 79.95$ (softbound)
}

\author{
Bruce A. Barron ${ }^{1}$
}

Published online: 23 June 2016

(c) Springer Science+Business Media New York 2016

This is the first edition of Rehabilitation: A Post-critical Approach authored by Barbara Gibson from the Department of Physical Therapy at the University of Toronto. The author is a physical therapist who has a doctorate in bioethics. Applying her education and training in physical therapy and bioethics, Gibson employs postmodern and post-critical theories to reevaluate and challenge the core concepts and philosophical foundations of rehabilitation.

To achieve the stated purpose of this book, the author uses movement literally and as a metaphor for ways to reform and change rehabilitation. In this first chapter, Gibson describes the post-critical approach as a process that challenges the prevailing principles, practices, and assumptions supporting Western science and rehabilitation. She makes frequent references to philosophers such as Kant, Marx, Hegel and Nietzsche and theorists such as Foucault to support her approach to reexamining modern-day rehabilitation.

Rehabilitation: A Post-critical Approach is organized into seven chapters; namely, Moving Rehabilitation, Disability/Normality, Quality of Life, Development, In/dependence, Mobilities, and Re-Forming Rehabilitation. Each chapter critically reviews and challenges current rehabilitation practices and principles. However, the author insinuates liberal philosophical viewpoints into the discussion that at times appear politically driven and biased. While Gibson's descriptions of modern practices are factual and well-referenced, her analyses lack scientific rigor and are theoretical; thereby limiting their application and value to real-world practice. Additionally the writing style is at times unclear, which is compounded by the fact that there are no tables or figures to facilitate the reader's understanding of complex information and arguments.

Overall, Rehabilitation: A Post-critical Approach is a hypothesis generating, theoretical book. As such, it has limited value for busy practitioners striving to provide high-quality patient care and optimal outcomes on a dayto-day basis. Indeed, this book was not published for those seeking pragmatic solutions to everyday clinical problems. Conversely, this book might be of interest to a select number of health care professionals seeking to explore the philosophical limitations of biomedicine, identify new approaches to rehabilitation, and ponder ethical issues in rehabilitation.
Bruce A. Barron

bruce_barron@urmc.rochester.edu

1 Division of Occupational and Environmental Medicine, School of Medicine and Dentistry, University of Rochester, Rochester, NY, USA 